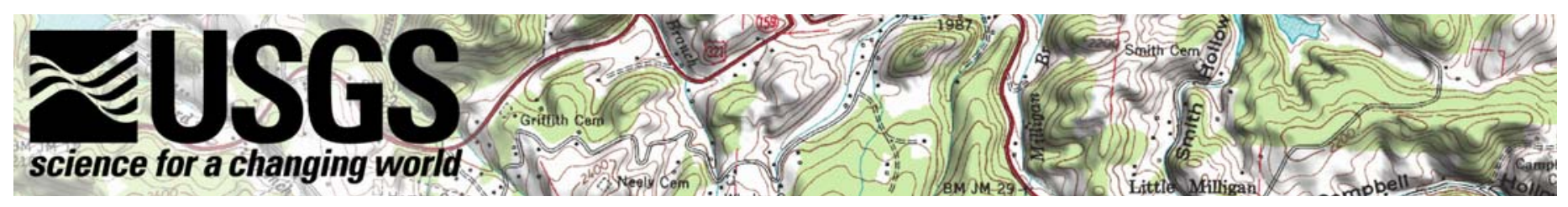

\title{
The National Map - Elevation
}

\section{The Nation Needs The National Map}

Governments depend on a common set of base geographic information as a tool for economic and community development, land and natural resource management, and health and safety services. Emergency management and homeland security applications rely on this information. Private industry, nongovernmental organizations, and individual citizens use the same geographic data. Geographic information underpins an increasingly large part of the Nation's economy.

Available geographic data often have the following problems:

Do not align with each other because layers are frequently created or revised separately,

Do not match across administrative boundaries because each producing organization uses different methods and standards, and

Are not up to date because of the complexity and cost of revision.

The U.S. Geological Survey (USGS) is developing The National Map to be a seamless, continuously maintained, and nationally consistent set of online, public domain, geographic base information to resolve these issues. The National Map will serve as a foundation for integrating, sharing, and using other data easily and consistently.

In collaboration with other Federal, State, county, and local government agencies, the private sector, academia, and the public, the USGS will coordinate, integrate, and, where needed, produce and maintain base geographic data.

The National Map will include digital orthorectified imagery, elevation data, vector data for hydrography, transportation, boundary, and structure features, geographic names, and land cover information. The data will be the source of revised paper topographic maps.

\section{National Elevation Dataset}

The National Elevation Dataset (NED) is a raster dataset that provides The

National Map elevation information in a seamless form with a consistent datum, elevation unit, and projection.

The original implementation of the NED was based on a data point spacing of 1 arc-second for the conterminous United States, Hawaii, and Puerto Rico, and a data point spacing of 2 arc-seconds for Alaska. NED data sources have a variety of elevation units, horizontal datums, and map projections. In the NED assembly process, the elevation values are converted to decimal meters as a consistent unit of measure. The NED data are cast in geographic coordinates, using NAD 83 as the horizontal datum and NAVD 88 as the vertical datum. Some source data used to assemble the NED were produced using methods that are now obsolete and that resulted in unwanted artifacts in the data. As part of NED assembly, custom filters are applied to minimize the transfer of these artifacts from the source data to the NED.

Artifact removal greatly improves the quality of the slope, shaded-relief, and synthetic drainage information that can be derived from the elevation data. NED processing also includes steps to adjust values where source data do not match well to provide seamless coverage.

These steps ensure that the NED has no void areas and that artificial discontinuities have been minimized.

The NED is a multiresolution dataset that is updated and improved, bimonthly, with higher resolution or higher quality elevation data. The 1-arc-second layer of the NED was built from 30-meter $(\sim 1$ arc-second) data and has been updated over large areas by integrating 10-meter source data, resampled to 1 arc-second.

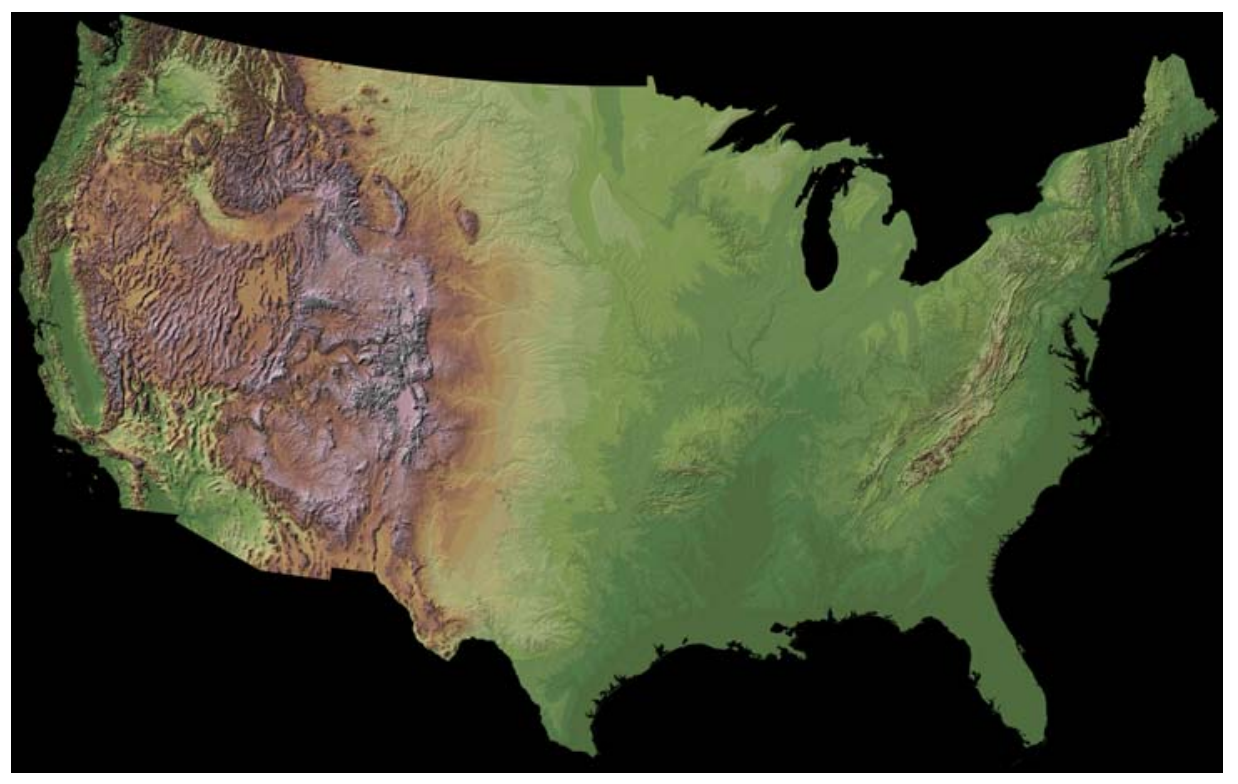

A shaded relief representation of the conterminous United States part of the National Elevation Dataset (NED). Elevation is shown as a range of colors, from dark green for low elevations to white for high elevations. 


\section{Metadata}

NED data are documented in conformance with the Federal Geographic Data Committee's Content Standard for Digital Geospatial Metadata. The footprint of each source dataset is retained during NED assembly to provide a spatial context. The native attributes of each source dataset, such as the original resolution and production method, as well as a description of the assembly process, are linked to these footprints. The set of footprints provides spatially referenced national metadata coverage. Through the metadata, information regarding the source data is available for any area of the NED. For example, a user can access the metadata to evaluate the source data over a project area to determine applicability of the NED to a given use.

\section{Applications of Elevation Data}

Elevation data are an essential part of many earth science applications. They are used for such diverse purposes as providing shaded-relief backgrounds, generating contours or synthetic drainage networks, classifying land cover, geometrically correcting remotely sensed data (orthophoto rectification), or deriving landform characteristics such as slope and aspect. Elevation data are critical to many modeling applications such as hydraulic and hydrologic studies, dispersion modeling, and predicting wild land fire behavior.

\section{Data Availability and Plans}

Elevation data are available from the NED in a seamless, nationally consistent form through the USGS Seamless Data Distribution System, seamless.usgs.gov.

The next-generation NED will offer multiple layers, at $1 / 3$ and $1 / 9$ arc-second ( $\sim 10$ and 3.3 meters). Where available, higher resolution data will replace the current NED content, providing a national multiresolution dataset. Higher resolution layers will be populated through the integration of data from various sources, using new technologies, and will be acquired through partnerships with Federal, State, and local partners, providing access to the best available local information.

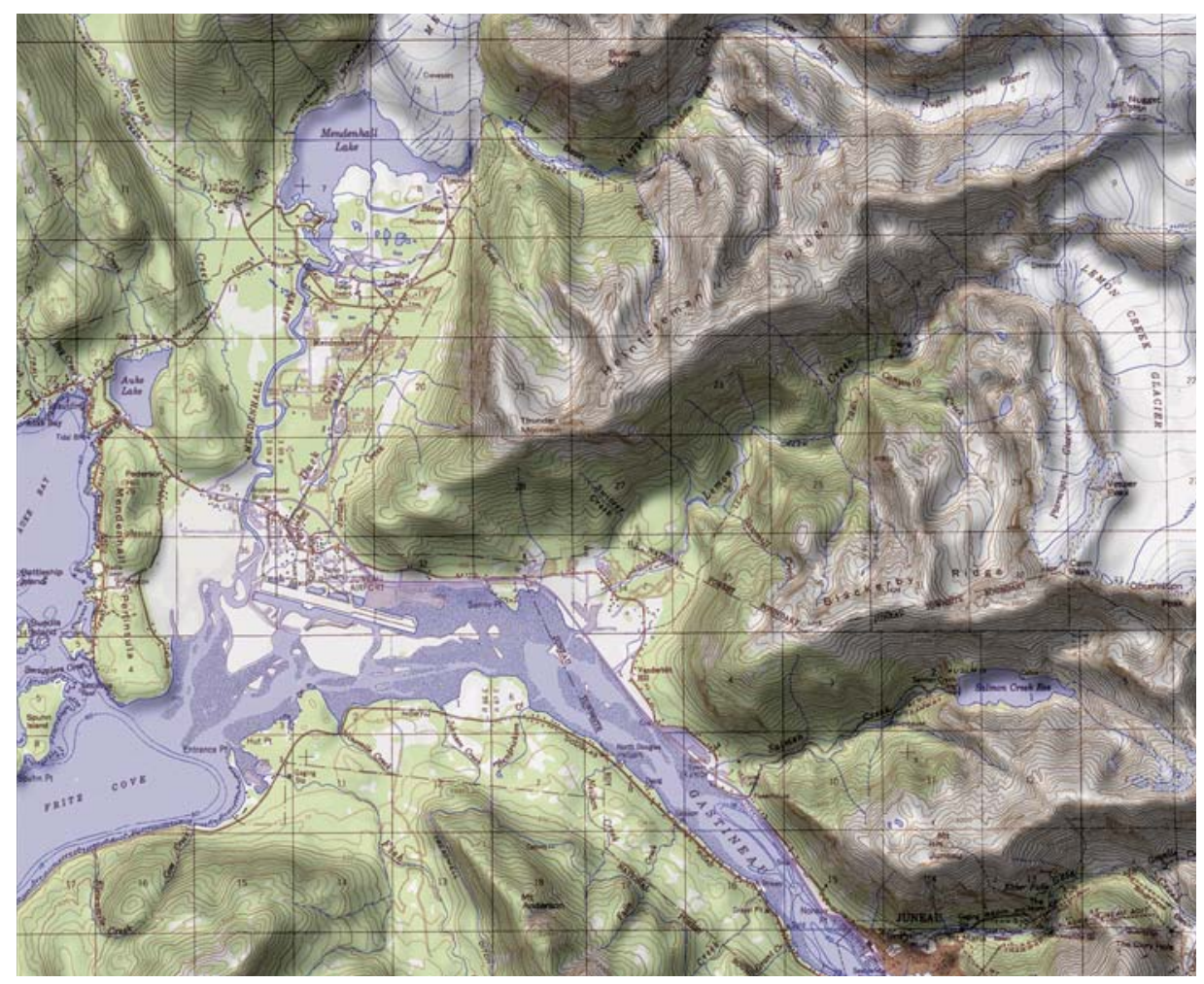

Shaded relief generated from raster elevation data effectively portrays the land surface, shown here in combination with the topographic map content from the USGS digital raster graphic of Juneau, Alaska.

\section{Partnership Opportunities}

Organizations interested in partnering with the USGS to develop elevation data for The National Map should contact the USGS mapping liaison in their State. The list of liaisons is available at mapping.usgs.gov/index.html\#partners. Click on "Mapping Partnership Program."

\section{Information}

Further information about The National Map and the National Elevation Dataset is available from the Cooperative Topographic Mapping Program, Mail Stop 511, USGS National Center, 12201 Sunrise Valley Drive, Reston, VA 20192. You can view and download more information about The National Map at nationalmap.usgs.gov.

For information on other USGS products and services, call 1-888-ASK-USGS or visit the general interest publications Web site on mapping, geography, and related topics at mac.usgs.gov/mac/isb/ pubs/pubslists/.
For additional information, visit the ask.usgs.gov Web site or the USGS home page at www.usgs.gov. 